\title{
Radiologic findings of thoracic trauma
}

This article was published in the following Dove Press journal:

Therapeutics and Clinical Risk Management

26 August 2017

Number of times this article has been viewed

\author{
Cihan Akgul Ozmen' \\ Serdar Onat ${ }^{2}$ \\ Delal Aycicek ${ }^{3}$ \\ 'Department of Radiology, \\ ${ }^{2}$ Department of Chest Surgery, \\ Dicle University School of Medicine, \\ Diyarbakir, ${ }^{3}$ Radiology Unit, Siirt State \\ Hospital, Siirt, Turkey
}

Introduction: Chest trauma may be blunt or penetrating and the chest is the third most common trauma region. It is a significant cause of mortality. Multidetector computed tomography (MDCT) has been an increasingly used method to evaluate chest trauma because of its high success in detecting tissue and organ injuries. Herein, we aimed to present MDCT findings in patients with blunt and penetrating chest trauma admitted to our department.

Methods: A total of 240 patients admitted to the emergency department of our hospital between April 2012 and July 2013 with a diagnosis of chest trauma who underwent MDCT evaluations were included. Most of the patients were male (83.3\%) and victims of a blunt chest trauma. The images were analyzed with respect to the presence of fractures of bony structures, hemothorax, pneumothorax, mediastinal organ injury, and pulmonary and vascular injuries.

Results: MDCT images of the 240 patients yielded a prevalence of $41.7 \%$ rib fractures, $11.2 \%$ scapular fractures, and $7.5 \%$ clavicle fractures. The prevalence of thoracic vertebral fracture was $13.8 \%$ and that of sternal fracture was $3.8 \%$. The prevalence of hemothorax, pneumothorax, pneumomediastinum, and subcutaneous emphysema was $34.6 \%, 62.1 \%, 9.6 \%$, and $35.4 \%$, respectively. The prevalence of rib, clavicle, and thoracic vertebral fractures and pulmonary contusion was higher in the blunt trauma group, whereas the prevalence of hemothorax, subcutaneous emphysema, diaphragmatic injury, and other vascular lacerations was significantly higher in the penetrating trauma group than in the blunt trauma group $(p<0.05)$.

Conclusion: MDCT images may yield a high prevalence of fracture of bony structures, soft tissue lacerations, and vascular lesions, which should be well understood by radiologists dealing with trauma.

Keywords: multidetector computed tomography (D061330), thoracic injuries (D013898) wounds, nonpenetrating (D014949), wounds, penetrating (D014950)

\section{Introduction}

Chest trauma is the third most common trauma type following trauma of head and extremities in polytrauma patients. ${ }^{1}$ Although in about half of the cases, the trauma is minor trauma, one-third of them require hospitalization. ${ }^{2}$ Chest trauma is categorized as blunt or penetrating according to the presence of injury in the chest wall. Penetrating trauma is rare and has a higher probability to be limited to the chest. Blunt chest trauma is directly responsible for $25 \%$ of all trauma-related deaths and is a major factor in another half of trauma-related mortality. ${ }^{3}$ Most blunt traumas are secondary to motor vehicle crashes $(63 \%-78 \%)$, and the remaining are caused by falls from heights $(10 \%-17 \%){ }^{4}$

Portable chest radiography is the first-line imaging method used for the emergency evaluation of a polytrauma patient. However, the superiority of computed tomography (CT) over chest radiography has been documented in the literature by the former's ability to demonstrate significant lesions in cases with normal initial radiography. ${ }^{5}$ Multidetector computed tomography (MDCT) has been an increasingly used method
Correspondence: Cihan Akgul Ozmen Dicle University School of Medicine, Department of Radiology, 21280

Diyarbakir, Turkey

Tel +90 4I2 248800 I

Email cihanakgul@gmail.com (c)
hereby accept the Terms. Non-commercial uses of the work are permitted without any further permission from Dove Medical Press Limited, provided the work is properly attributed. For permission for commercial use of this work, please see paragraphs 4.2 and 5 of our Terms (https://www.dovepress.com/terms.php).
s. 
to evaluate chest trauma in polytrauma subjects owing to its significantly better ability in detecting tissue and organ injuries than chest radiography. ${ }^{2,6,7}$ Furthermore, the utilization of MDCT is increasing in blunt chest trauma injury cases and leading detection of significant lesions. However, the significance of the lesions is not so much demonstrated for blunt chest traumas. ${ }^{8}$

Because MDCT has been established as the gold standard for imaging evaluation of chest trauma and is used more frequently, radiologists should better familiarize themselves with MDCT findings of chest trauma. Herein, we aimed to present the MDCT findings in patients with blunt and penetrating chest trauma admitted to our department.

\section{Methods}

This retrospective study includes 240 patients admitted to the emergency department of our hospital between April 2012 and July 2013 with a diagnosis of chest trauma who underwent an MDCT evaluation. Patient demographics, including age, gender, and type of injury, were obtained from the hospital's medical records. Most of the patients were male $(n=200,83.3 \%)$ and victims of a blunt chest trauma. The major type was blunt chest trauma $(78.3 \%)$, with penetrating type in $21.7 \%$ of patients. Most of the blunt traumas were caused by motor vehicle crashes $(n=115,61.2 \%)$, while falls from heights $(n=59,31.4 \%)$ was the second most frequent cause. The most common cause of penetrating chest trauma was stab injury $(n=32,61.5 \%)$.

All imaging findings of the 240 patients who underwent MDCT with 16-MDCT Toshiba Aquilion (Toshiba Medical Systems Corporation) and 64-MDCT scanner (Brilliance CT scanner; Philips Healthcare) were analyzed with respect to the presence of fractures of bony structures (rib, scapula, clavicle, sternum, and thoracic vertebra), hemothorax, pneumothorax, mediastinal organ injury, and pulmonary, tracheal, abdominal, aortic, and vascular lacerations.

All images were obtained from the picture archiving and communication system (PACS) and evaluated at the work station. We used sagittal, coronal, and volume-rendered reformatted images beside the axial images.

Continuous variables were expressed as mean \pm standard deviation and frequencies as percentages. Categorical variables of blunt and penetrating trauma were compared using the chi-squared test. Fisher's exact test was used for statistical significance when a value $<5$ was present in the $2 \times 2$ table. A $p$-value $<0.05$ was considered as statistically significant.

\section{Ethics}

Ethics committee approval and patient consent are not required by regulations in Turkey for studies with a retrospective design. Dicle University School of Medicine Board has reviewed and confirmed this study as retrospective and waived approval. Patient data used were anonymized.

\section{Results}

Rib fractures were diagnosed in 100 (41.7\%) patients, of whom 44 had right-sided rib fractures and 40 had left-sided rib fractures; $6.7 \%$ had bilateral rib fractures on MDCT images (Figure 1). Scapular fracture was detected in 11.2\% of the patients and clavicle fractures in $7.5 \%$ of the patients (Figure 2). The percentages of thoracic vertebral and sternal fractures were $13.8 \%(n=33)$ and $3.8 \%$ in the entire study population.

The prevalence of hemothorax, pneumothorax, pneumomediastinum, and subcutaneous emphysema was $34.6 \%$, $62.1 \%, 9.6 \%$, and $35.4 \%$, respectively.

Pulmonary contusion diagnosed in $55.8 \%(n=134)$ cases was right sided in 39 cases and left sided in 37 cases. Pulmonary laceration was present in 47 (19.6\%) cases (Figure 3). Bronchial lacerations were rare $(1.6 \%)$. The most common types of pulmonary lacerations were Type $1(n=22)$ and Type $2(n=19)$.

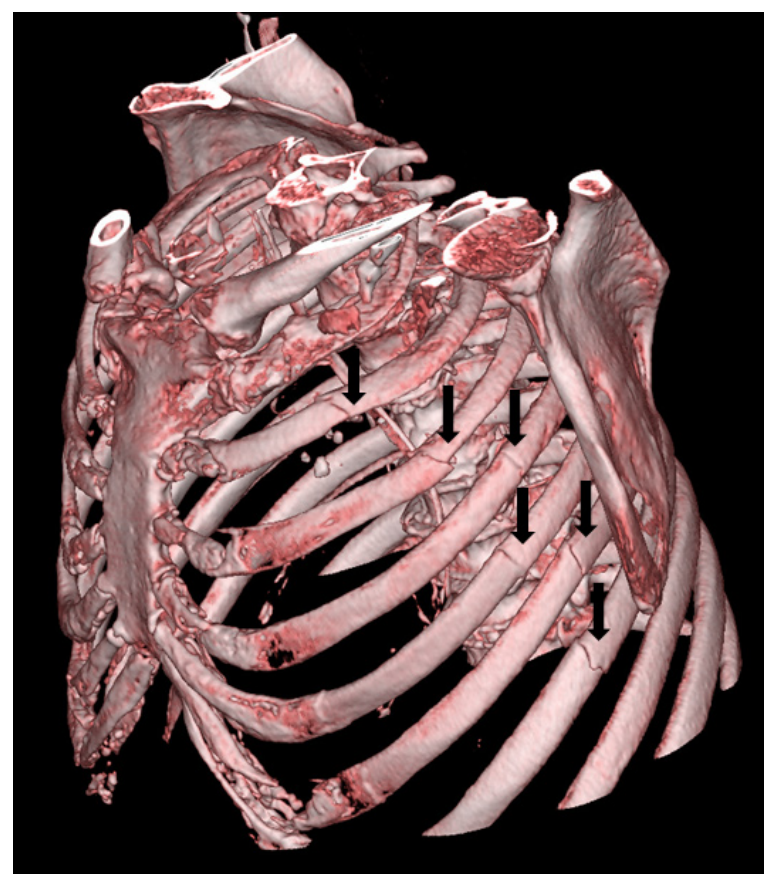

Figure I An 82-year-old woman who suffered from a motor vehicle accident. Note: Serial rib fractures are seen on the volume-rendered reconstructed image (black arrows). 


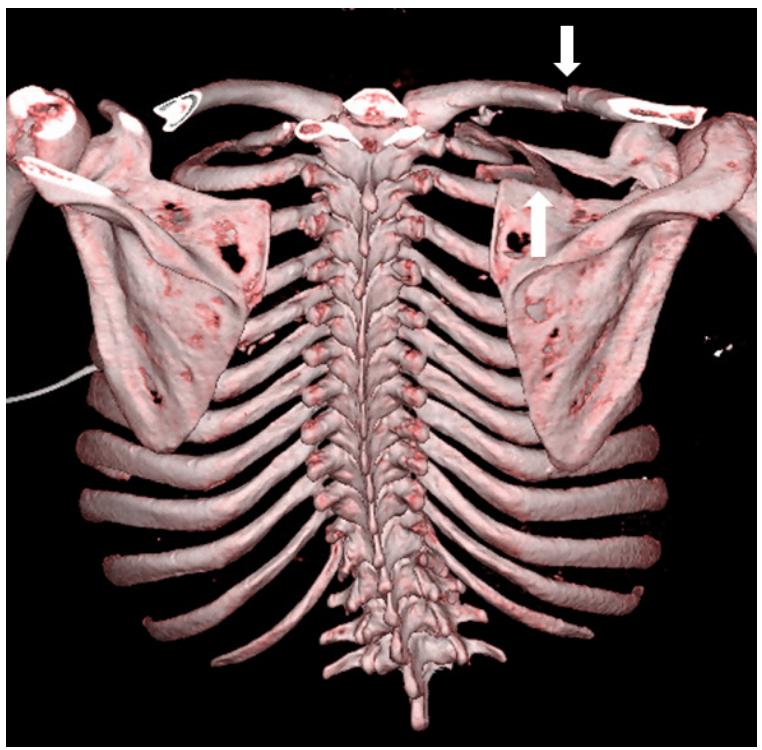

Figure 2 A 35-year-old man who fell from a height.

Note: A volume-rendered image view from the posterior aspect demonstrates right clavicle and scapula fractures (white arrows).

The prevalence of sternal fracture not diagnosed by axial images but diagnosed by sagittal reformatted images was $33.3 \%$. Although we were able to diagnose all of the spinous and transverse process fractures of thoracic vertebrae by axial images, sagittal and coronal reformatted images were required in $24.2 \%$ of the cases with vertebral body compression fracture.

Diaphragmatic injury occurred in 4.2 of our cases (Figure 4). We did not detect any aortic, tracheal, or pulmonary artery injury in any patient. The most commonly injured abdominal organs were the liver $(n=23)$ and spleen $(n=17)$ among the chest trauma patients.

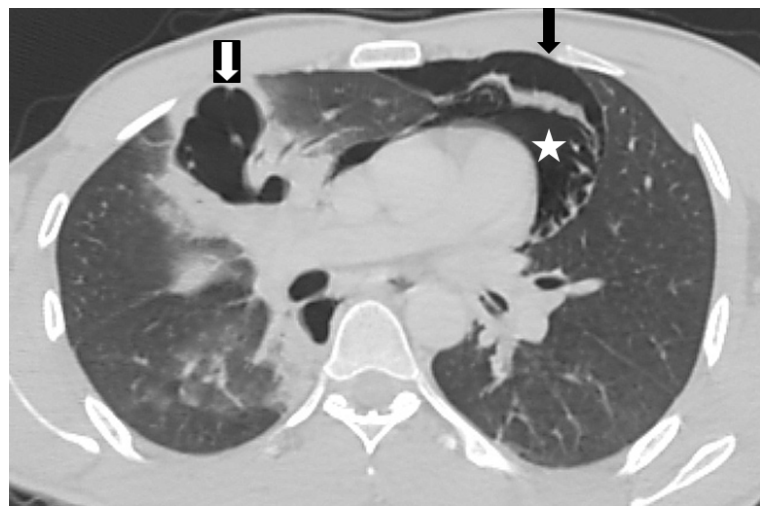

Figure 3 A 33-year-old man who had a motor vehicle crash had right lung laceration (white arrow) and surrounding contusion.

Note: The figure also shows pneumothorax (black arrow) and pneumomediastinum (star).

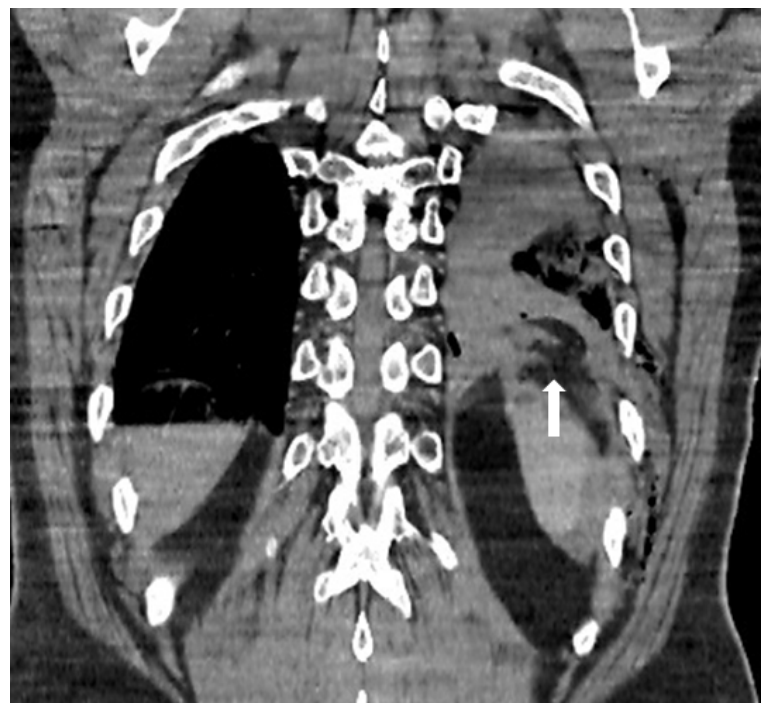

Figure 4 A 36-year-old man with penetrating trauma.

Note: There is a small defect on the left hemidiaphragm (arrow) and herniation of the intra-abdominal fat to the left hemithorax on the coronal-reconstructed CT images.

Abbreviation: $\mathrm{CT}$, computed tomography.

We detected significantly higher rates of rib fracture, clavicle fracture, thoracic vertebral fracture, and pulmonary contusion in the blunt trauma group than in the penetrating trauma group $(p<0.05)$. However, rates of hemothorax, subcutaneous emphysema, diaphragmatic injury, and other vascular lacerations were significantly higher in the penetrating trauma group than in the blunt trauma group $(p<0.05$; Table 1).

Table I Comparison of MDCT findings in blunt and penetrating trauma groups

\begin{tabular}{|c|c|c|c|}
\hline Trauma findings & $\begin{array}{l}\text { Blunt } \\
\text { trauma } \\
(n=\mid 88)\end{array}$ & $\begin{array}{l}\text { Penetrating } \\
\text { trauma } \\
(n=52)\end{array}$ & $p$-value \\
\hline Rib fracture (\%) & 48.4 & 17.3 & $<0.0001$ \\
\hline Scapular fracture (\%) & 12.2 & 7.7 & ns \\
\hline Clavicle fracture (\%) & 9.6 & 0 & 0.016 \\
\hline Thoracic vertebral fracture (\%) & 17.6 & 0 & $<0.0001$ \\
\hline Sternal fracture $(\%)$ & 4.8 & 0 & ns \\
\hline Hemothorax (\%) & 30.9 & 48.1 & 0.021 \\
\hline Pneumothorax (\%) & 61.7 & 63.5 & ns \\
\hline Pneumomediastinum (\%) & 9.0 & 11.5 & ns \\
\hline Subcutaneous emphysema (\%) & 20.7 & 88.5 & $<0.000$ I \\
\hline Pulmonary contusion (\%) & 62.2 & 32.7 & $<0.0001$ \\
\hline Pulmonary laceration (\%) & 19.1 & 21.2 & ns \\
\hline Bronchial lacerations (\%) & I.I & 3.8 & ns \\
\hline Other vascular lacerations (\%) & 0.5 & 5.8 & 0.033 \\
\hline Diaphragmatic injury (\%) & 0.5 & 17.3 & $<0.0001$ \\
\hline Abdominal organ laceration (\%) & 31.9 & 32.7 & ns \\
\hline
\end{tabular}

Abbreviations: MDCT, multidetector computed tomography; ns, nonsignificant. 


\section{Discussion}

Rib fracture is the most common injury in blunt chest trauma, and CT is the best method of visualization. ${ }^{5}$ Rib fractures have been detected in half of the patients with blunt chest trauma. ${ }^{1,9,10}$ Rib fractures were detected in $41.7 \%$ of the total cohort, with $48.7 \%$ in the blunt trauma group and $14.3 \%$ in the penetrating chest trauma group. Demirhan et $\mathrm{al}^{11}$ reported rib fractures in $34 \%$ of 4,205 patients, which is lower than that reported in our study. The low ratio of patients with blunt trauma in their study (66\% vs $78.3 \%$ ) may account for the difference.

Scapular fracture is a rare finding in patients with chest trauma and has been reported in $3.7 \%-7.9 \%$ of those with blunt chest trauma. ${ }^{1,9-12}$ The ratio of patients with scapular fractures in the blunt and penetrating groups was $12.2 \%$ and $7.7 \%$, respectively. Sternal fractures have been reported in $3 \%-8 \%$ of blunt chest trauma cases. ${ }^{9-12}$ It is difficult to detect sternal fractures on chest radiographs and even on axial CT images. However, sagittal and coronal MDCT reformats are significantly superior in detecting sternal fractures. A prevalence of $4.8 \%$ in our blunt trauma group is consistent with the literature. No case of sternal fracture was detected in our penetrating chest trauma group.

Thoracolumbar vertebrae fractures have been detected in $18 \%$ of patients with blunt chest trauma. ${ }^{12}$ This number was reported to be $27.9 \%$ in a study by Turkalj et al ${ }^{13}$ that included 62 patients. Our study reported $17.6 \%$ thoracolumbar vertebral fractures in the blunt trauma group, consistent with the literature. Hemothorax is a common finding and may be present in up to half of the cases. ${ }^{9}$ In our study, it was higher in the penetrating trauma group with a ratio of $48.1 \%$. Trauma-related pneumothorax has been reported in a wide range of patients (15\%-50\%) and mostly caused rib fractures leading to lacerations. ${ }^{1,9,13}$ It was detected with similar rates of $62 \%$ and $63 \%$ in blunt and penetrating trauma groups, respectively, in our study. The prevalence of pneumomediastinum in blunt trauma is $10 \%$ in the literature, ${ }^{9}$ which is similar to the value of $9.6 \%$ reported in our cohort.

Patients with blunt chest trauma are reported to have a 15\%-34\% prevalence of subcutaneous emphysema. ${ }^{12,13}$ This was similar to that observed in our blunt trauma group that had a subcutaneous emphysema prevalence of $20.7 \%$, while in the penetrating trauma group, the prevalence was $88.5 \%$.

Pulmonary contusion is the most common lung injury in patients with blunt chest trauma, with a prevalence of $17 \%-70 \%$, and is seen more commonly than pulmonary laceration. ${ }^{1,5}$ The prevalence of pulmonary contusion was $62.2 \%$ in the blunt trauma group, which is significantly higher than the penetrating group (32.7\%). Pulmonary laceration was detected in similar frequencies in both groups.

In one-third of patients with sternal and thoracic vertebral fractures, we demonstrated the benefits of sagittal and coronal reformatted images made available by the MDCT technique with no additional radiation exposure. Volumerendered images were used to comprehensively evaluate patients with multiple rib fractures. In the trauma setting, a complicated chest wall fracture can be better evaluated with this technique.

Diaphragmatic injuries are rare, with a prevalence of $0.16 \%-5 \%$ in blunt chest trauma and more common in penetrating traumas. ${ }^{1,5,9}$ The prevalence was $0.5 \%$ in our subjects with blunt trauma. However, it was high (17.3\%) in the penetrating group.

Tracheobronchial injuries are rarely seen in clinical practice because of high prehospital mortality. They have been reported in $0.2 \%-8 \%$ of patients with blunt chest trauma. ${ }^{1,9,13-15}$ Esophageal injury is extremely rare, because the esophagus is well protected in the mediastinum. Most esophageal injuries occur from penetrating chest traumas with a prevalence of $1 \%-1.6 \% .{ }^{9,13}$ We detected just one case of esophageal injury among the 240 subjects. The retrospective nature of our study is the major limitation.

\section{Conclusion}

Chest trauma is a common trauma type with high mortality in polytrauma patients, and MDCT has been increasingly used to evaluate chest trauma in these cases owing to its superior performance in detecting tissue and organ injuries compared with chest radiography. MDCT images may yield high prevalence of fracture of bony structures, soft tissue lacerations, and vascular lesions, which should be well understood by radiologists dealing with trauma.

\section{Disclosure}

The authors report no conflicts of interest in this work.

\section{References}

1. Kaewlai R, Avery LL, Asrani AV, Novelline RA. Multidetector CT of blunt thoracic trauma. Radiographics. 2008;28(6):1555-1570.

2. Chapman BC, Overbey DM, Tesfalidet F, et al. Clinical utility of chest computed tomography in patients with rib fractures CT chest and rib fractures. Arch Trauma Res. 2016;5(4):e37070.

3. Scaglione M, Pinto A, Pedrosa I, Sparano A, Romano L. Multi-detector row computed tomography and blunt chest trauma. Eur J Radiol. 2008; 65(3):377-388

4. Mayberry JC. Imaging in thoracic trauma: the trauma surgeon's perspective. J Thorac Imag. 2000;15:76-86.

5. Sridhar S, Raptis C, Bhalla S. Imaging of blunt thoracic trauma. Semin Roentgenol. 2016;51(3):203-214. 
6. Trupka A, Waydhas C, Hallfeldt KK, Nast-Kolb D, Pfeifer KJ, Schweiberer L. Value of thoracic computed tomography in the first assessment of severely injured patients with blunt chest trauma: results of a prospective study. J Trauma. 1997;43(3):405-411. Discussion 411-412.

7. Kim SJ, Bista AB, Min YG, et al. Usefulness of low dose chest CT for initial evaluation of blunt chest trauma. Medicine (Baltimore). 2017; 96(2):e5888.

8. Mollberg NM, Wise SR, De Hoyos AL, Lin FJ, Merlotti G, Massad MG. Chest computed tomography for penetrating thoracic trauma after normal screening chest roentgenogram. Ann Thorac Surg. 2012;93(6): 1830-1835.

9. Oikonomou A, Prassopoulos P. CT imaging of blunt chest trauma. Insights Imaging. 2011;2(3):281-295.

10. Afacan MA, Buyukcam F, Cavus UY, et al. Acil Servise Başvuran Künt Toraks Travma Vakalarının İncelen [The evaluation of patients with blunt thoracic trauma in the emergency room]. Kocatepe Med J. 2012;13:19-25. Turkish.
11. Demirhan R, Onan B, Oz K, Halezeroglu S. Comprehensive analysis of 4205 patients with chest trauma: a 10-year experience. Interact Cardiovasc Thorac Surg. 2009;9(3):450-453.

12. Wirth $\mathrm{S}$, Jahnsen $\mathrm{S}$. Bony and thoracic chest wall injuries. In: Mariano Scagliono M, Linsenmaier U, Schueller G, Wirth S, editors. Bony and Thoracic Chest Wall Injuries. 1st ed. Switzerland: Springer; 2017: 25-59.

13. Turkalj I, Petrović K, Stojanović S, Petrović D, Brakus A, Ristić J. Blunt chest trauma - an audit of injuries diagnosed by the MDCT examination. Vojnosanit Pregl. 2014;71(2):161-166.

14. Burack JH, Kandil E, Sawas A, et al. Triage and outcome of patients with mediastinal penetrating trauma. Ann Thorac Surg. 2007;83(2):377-382.

15. Gunn ML, Clark RT, Sadro CT, Linnau KF, Sandstrom CK. Current concepts in imaging evaluation of penetrating transmediastinal injury. Radiographics. 2014;34(7):1824-1841.
Therapeutics and Clinical Risk Management

\section{Publish your work in this journal}

Therapeutics and Clinical Risk Management is an international, peerreviewed journal of clinical therapeutics and risk management, focusing on concise rapid reporting of clinical studies in all therapeutic areas outcomes, safety, and programs for the effective, safe, and sustained use of medicines. This journal is indexed on PubMed Central, CAS,

\section{Dovepress}

EMBase, Scopus and the Elsevier Bibliographic databases. The manuscript management system is completely online and includes a very quick and fair peer-review system, which is all easy to use. Visit http://www.dovepress.com/testimonials.php to read real quotes from published authors.

Submit your manuscript here: http://www.dovepress.com/therapeutics-and-clinical-risk-management-journal 